\title{
Surgical Approach to Parapharyngeal Tumours - Our Experience
}

\author{
Devjani Ghosh Shrestha, ${ }^{1}$ Kinjal Shankar Majumdar, ${ }^{1}$ Nirmalya Samanta, ${ }^{1}$ Utpal Jana ${ }^{2}$
}

\section{Introduction}

\section{$\underline{\text { ABSTRACT }}$}

The complex anatomy of the parapharyngeal space, the surrounding vital structures and late presentation of the tumours affecting this space pose difficult surgical challenge to every otolaryngologist. The study gives an overview of the experience in managing parapharyngeal tumours in a tertiary care setting.

\section{Materials And Methods}

Fifteen patients with parapharyngeal tumours were treated surgically in a medical college hospital in Kolkata in the three year study period. Surgical approaches were chosen, considering the size, site, extent and histology of the tumours.

$\underline{\text { Results }}$

Most of the patients (33.33\%) were from 20-30 years age group. $60 \%$ were females. The most common presenting feature was neck swelling. $80 \%$ of the cases were benign. The most common histologic variant was Schwannoma. The tumours were accessed through Trans-cervical, Trans-cervical Trans-parotid or Trans-cervical with Midline Mandibulotomy approaches. The most common post-operative complication was wound dehiscence.

\section{Discussion}

The most common presentation of a parapharyngeal mass was neck swelling mainly behind the angle of mandible (86.67\%). Younger patients in their third decade of life were found to be affected more. Gadolinium enhanced MRI was found to be the most important investigation in parapharyngeal tumours. Complications were minimal.

\section{Conclusion}

A conservative trans-cervical approach was found to be feasible and effective in majority of the cases over radical ones, which may be required in malignancies and skull-base involvement.

$\underline{\text { Kevwords }}$

Neck; Neoplasms; Parapharyngeal tumours; surgical procedures; operative; Neurilemmoma; Paraganglioma ; Carcinoma; Adenoma, Pleomorphic

$\mathrm{T}$ umours of the parapharyngeal space pose a surgical challenge to every otolaryngologist. These tumours constitute only $0.5 \%$ all head and neck tumours, with $80 \%$ being benign in nature. ${ }^{1,2}$ The most common histological type reported is Pleomorphic Adenoma involving the deep lobe of parotid gland, although some authors have found Paraganglioma to be the most common histological finding. ${ }^{3,4,5,6}$ Delayed presentation complicates the procedure.

Different authors have suggested different approaches for successful surgical removal., ${ }^{4,5,7,8,9}$ Here, we present our experience in the management of those tumours.

\section{Materials and methods}

Fifteen adult patients with parapharyngeal swelling, successfully managed surgically, over a period of 3 years from March, 2011 to February, 2014 in a teaching hospital in Kolkata, were reviewed. Careful intra-oral and cervical examinations (including bi-manual palpation) were carried out to assess the extent and consistency of the tumour. Neurological examination was done to exclude involvement of lower four cranial nerves and cervical sympathetic chain. The patients were subjected to routine investigations, imaging (MRI / CT Scan) and FNAC. MR Angiography was done in selected patients

1 - Department of ENT, NRS Medical College, Kolkata 2 - Departtment of ENT, Sagar Dutta Medical College, Kamarhati

\section{Corresponding author:}

Dr Devjani Ghosh Shrestha

email: devjani_g2000@yahoo.com 
suspected of vascular tumour or paraganglioma only.

The type of operative approach was determined based on the size, site, extent and pre-operative diagnosis of the tumour. The patients were followed up post-operatively after 1 month, 3 months, 6 months and 1 year.

\section{Results}

In our study, the most common age group of presentation was 20 - 30 years i.e. 5 patients $(33.33 \%)$. Nine cases $(60 \%)$ were females and 6 cases were males $(40 \%)$. The most common presenting symptom in our study was neck swelling (Fig. 1), followed by intra-oral swelling

Table I: Clinical presentations of parapharyngeal tumours

\begin{tabular}{|c|c|c|}
$\begin{array}{c}\text { C L I N C A L } \\
\text { PRESENTATION }\end{array}$ & $\begin{array}{c}\text { NO. OF } \\
\text { CASES }\end{array}$ & $\begin{array}{c}\text { PERCENTAGE } \\
\text { (\%) }\end{array}$ \\
\hline Neck Swelling & 13 & 86.66 \\
\hline Intra-oral Swelling & 9 & 60 \\
\hline Muffled Voice & 7 & 46.66 \\
\hline Dysphagia & 7 & 46.66 \\
\hline Horner's Syndrome & 2 & 13.33 \\
\hline Pain & 2 & 13.33 \\
\hline $\begin{array}{c}\text { Cranial Nerve } \\
\text { Palsy }\end{array}$ & 2 & 13.33 \\
\hline $\begin{array}{c}\text { Symptoms of } \\
\text { Catecholamine } \\
\text { excess }\end{array}$ & 2 & 13.33 \\
\hline Trismus & 1 & 6.66 \\
\hline
\end{tabular}

(Fig. 2), muffled voice, dysphagia, Horner's Syndrome, pain, cranial nerve palsy, symptoms of Catecholamine excess and trismus (Table I).

The most common histologic variant in our study was Schwannoma i.e. 6 cases $(40 \%)$, followed by
Pleomorphic adenoma in 4 cases $(26.67 \%)$ (Table II). Of these cases, 10 were seen in pre-styloid compartment and 5 in post-styloid compartment in a ratio of $2: 1$. Of the 6 cases of schwannoma, 4 cases were pre-styloid and 2 cases were post-styloid in origin.

Depending upon the size, site, extent and histology of the tumours, various surgical approaches were selected. The most common surgical approach that we used was the Trans-cervical approach -9 cases $(60 \%)$, followed by Trans-cervical Trans-parotid - 3 cases (20\%) and Trans-cervical with Midline Mandibulotomy - 2 cases (13.33\%). 1 case of Carotid body tumour was referred out to the Department of Cardio-Thoracic Surgery for further management.

The most common post-operative complication in our study was wound dehiscence in 4 cases $(26.67 \%)$, followed by Facial nerve palsy in 2 cases (13.33\%) and trismus in 2 cases $(13.33 \%)$. Whereas, Vagus nerve

Table II: Histologic variants of parapharyngeal tumours

\begin{tabular}{|c|c|c|}
\hline $\begin{array}{c}\text { HISTOLOGY OF } \\
\text { TUMOURS }\end{array}$ & $\begin{array}{c}\text { NO. OF } \\
\text { CASES }\end{array}$ & $\begin{array}{c}\text { PERCENTAGE } \\
(\%)\end{array}$ \\
\hline Schwannoma & 6 & 40 \\
\hline Salivary Tumour & 4 & 26.66 \\
\hline Paraganglioma & 2 & 13.33 \\
\hline $\begin{array}{c}\text { Carotid Body } \\
\text { Tumour }\end{array}$ & 1 & 6.66 \\
\hline $\begin{array}{c}\text { Adenoid Cystic } \\
\text { Carcinoma }\end{array}$ & 1 & 6.66 \\
\hline $\begin{array}{c}\text { Metastatic } \\
\text { Carcinoma }\end{array}$ & 1 & 6.66 \\
\hline
\end{tabular}

palsy and Sympathetic chain involvement (Horner's syndrome) were seen in 1 case each $(6.67 \%)$.

\section{Discussion}

Parapharyngeal space is an anatomically complex inverted pyramid shaped area where the base is formed by lateral skull-base including basisphenoid and apex 


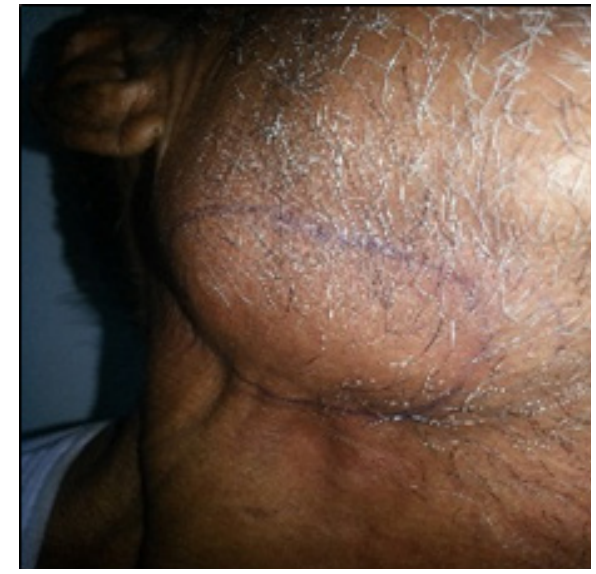

Fig. 1 Neck Swelling

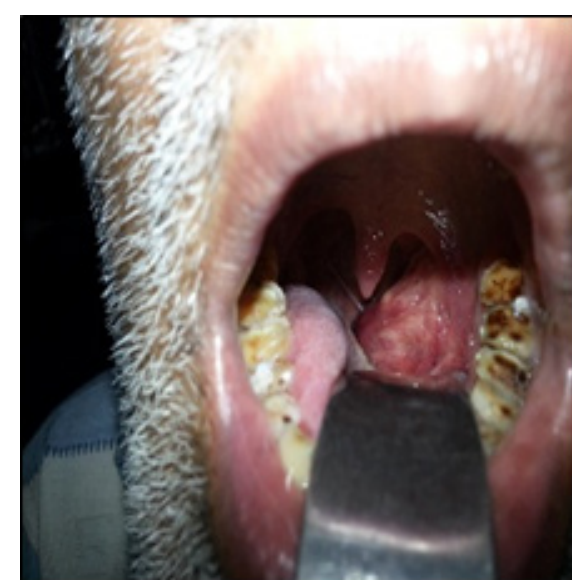

Fig. 2 Intraoral Swelling

is formed at the greater cornu of the Hyoid bone. Styloid process, more precisely Tensor veli palatini fascia covering the muscle divides the space into prestyloid and post-styloid compartments. Most of the vital structures like Internal Carotid artery, Internal Jugular vein, lower four cranial nerves and sympathetic trunk are present in the posterior compartment; whereas deep lobe of parotid gland and some lymph nodes reside in the anterior compartment. $4,6,7$

As most of the lesions in the parapharyngeal space are benign and tend to present late in its course, the most common age group of presentation is 4th and 5th decades of life. ${ }^{4,6,7,10}$ On the contrary, in our study, the most common age group of presentation was $20-30$ years. This may be due to small sample size $(n=15)$ and majority of the cases being schwannoma, which are most commonly found in $20-35$ years age group. ${ }^{11}$

A slight female preponderance $(\mathrm{F}: \mathrm{M}=1.5: 1)$ has been noted in this series, which correlates well with various other studies. .,6,7,10,12 $^{2}$

Parapharyngeal mass can give rise to a host of various symptoms depending on the different types of adjacent structures affected. In our study, the most common presentation was neck swelling mainly behind the angle of mandible $(86.67 \%)$, which is in accordance with various published series. ${ }^{5,6,7,8,12}$ This may be explained by the fact that the only resilient wall of parapharyngeal space is the medial wall. Rest of the walls are too rigid to cause any significant distortion by the tumour. ${ }^{4}$ Although most of the cases that we came across were schwannomas which generally present with cervical swellings, their moderate size in most cases initially leads to intra-oral bulging rather than cervical swelling. Trismus indicates infiltration of the Pterygoid muscles in malignancies or mechanical obstruction to coronoid process. It was seen in only 1 case $(6.67 \%)$ of adenoid cystic carcinoma in our study.

The next most common symptoms were dysphagia (46.67\%) and muffled voice (46.67\%). Cranial nerve palsies were seen in 2 cases $(13.33 \%)$. These occur due to the involvement of the lower four cranial nerves in the post-styloid compartment. Involvement of the 9th (Glossopharyngeal) and 10th (Vagus) cranial nerves are more common which gives rise to nasal regurgitation, nasal intonation, hoarseness, flattening of palatal arch and dysphonia. It may be due to mass compression effect and their presence usually signifies malignancy or Paraganglioma as seen in two of our cases. ${ }^{13}$

Gadolinium enhanced MRI is the most important investigation. It is done to find out the site of origin, size, extent and involvement of the surrounding vital structures especially the Carotid sheath and its contents, lower four cranial nerves and cervical sympathetic chain. Due to its superior soft tissue contrast, MRI is better than Contrast Enhanced CT Scan (CECT); ${ }^{14}$ the only drawback being its poor bony detail, for which CT is better. So in extensive tumours, extending upto the lateral skull-base, CT Scan is an useful adjunct to figure out Jugular foramen, Hypoglossal foramen and 
Foramen lacerum areas.

A non-parotid pre-styloid parapharyngeal mass can be easily differentiated from a deep lobe parotid mass radiologically by a thin radiolucent line between the parotid capsule and the mass, which is absent in nonparotid lesions.

MR Angiography (Fig. 3) was done in four of our cases clinically suspected of having vascular tumour or encroachment of carotid sheath by the tumour. It is usually done in suspected case of paraganglioma including carotid body tumour. ${ }^{4,7}$

Fine Needle Aspiration Cytology (FNAC) was done in all cases externally or intra-orally, depending upon the managed by this approach due to insufficient exposure superiorly. ${ }^{4,5,7,8}$ However, in our experience, we found this to be the most practical approach, since not only small and moderate tumours but even large tumours, especially well encapsulated ones, can be approached trans-cervically with little difficulty and can be dissected out bluntly without causing significant injury to great vessels and nerves.

Second most commonly used approach was Transcervical Trans-parotid (Fig.5). Lateral mandibulotomy can be combined with this, if deemed necessary. This is particularly suitable for salivary gland tumours arising from the deep lobe of parotid gland. Facial nerve poses a certain difficulty and injury is quite common
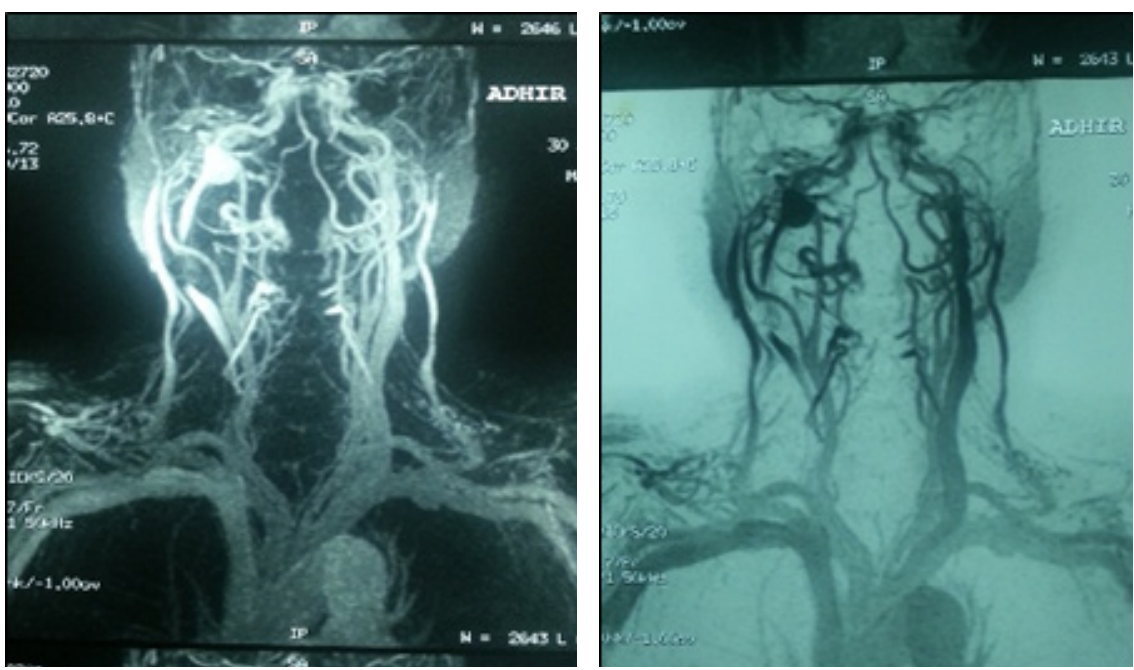

Fig. 3 MR Angiography showing lateralization of Internal Jugular Vein by the tumour

clinical presentation for pre-operative tissue diagnosis. FNAC bears overall Sensitivity of $96 \%$ and Specificity of $99 \%$ with Accuracy being $98.8 \% .^{15}$ However, FNAC suffers the drawback of yielding false positive or false negative results, especially in cases of paraganglioma. Incisional biopsy is usually avoided.

Sixty percent of the tumours in this series were excised through Trans-cervical approach (Fig. 4). As per existing literature, exposure through this approach is limited superiorly by the angle of mandible. It is suitable for only small and moderate sized tumours. Tumours extending up to the skull-base cannot be even in experienced hands. ${ }^{4,7,10}$ Out of three patients approached by this method, two patients developed Facial nerve palsy, out of which, 1 patient recovered by administration of steroids post-operatively.

Third type of approach used was Trans-cervical Midline Mandibulotomy (Fig. 6). It provides excellent exposure for extensive tumours involving the lateral skull-base. ${ }^{4,8,9}$ This approach is also known as 'Mandibular swing'. Extensive resection and ligation of major vessels is very well feasible. Repositioning and wire or plate and screw fixation of the mandible gives satisfactory cosmetic outcome. Our experience says that this approach is an excellent one in cases of 
skull-base involvement as it gives enough exposure for complete removal of the tumour. However, it is more time consuming and chances of complications like wound dehiscence, marginal mandibular nerve injury, palate and dental complications are more, adding to the morbidity of the patient. ${ }^{15}$

The post-operative complications were very few. Most

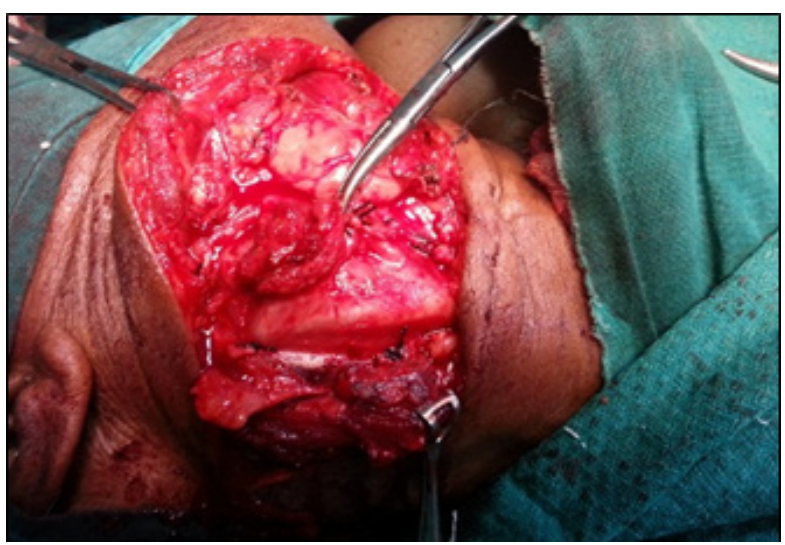

Fig. 4 Trans-cervical Approach

common complication was wound dehiscence, seen in 4 cases $(26.67 \%)$. 2 cases of vocal cord palsy were seen in cases of vagal paraganglioma. One out these 2 cases opted for Medialization (Type-I) Thyroplasty later on.

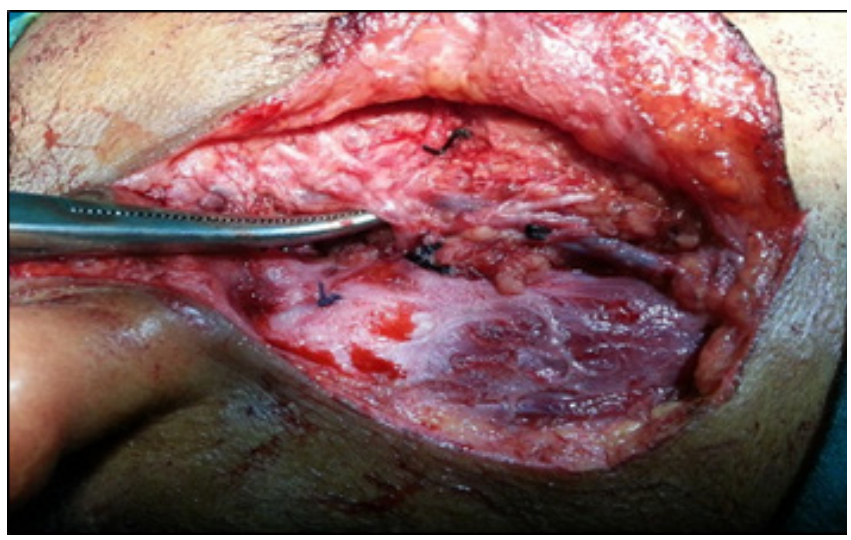

Fig. 5 Trans-cervical Trans-parotid Approach

\section{Conclusion}

From our study, we conclude that not only small to moderate sized parapharyngeal tumours but also large

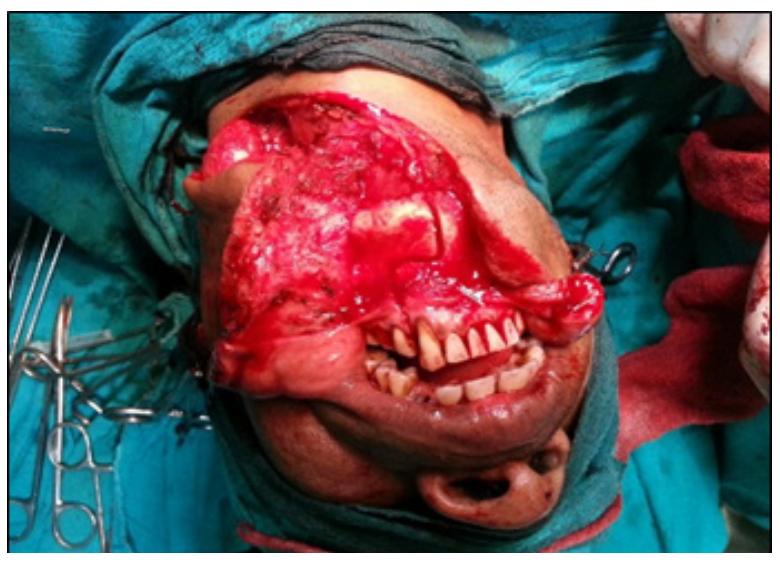

Fig. 6 Trans-cervical Midline Mandibulotomy Approach

tumours, especially benign and well encapsulated ones, are quite well managed by an adequate Transcervical approach. Only Malignancies or Skull-base involvement entails a more radical approach like Transcervical Midline Mandibulotomy. Hence, a conservative and conventional Trans-cervical approach is feasible in most of the cases over an extensive and radical one.

\section{References}

1. Bozza F, Vigili MG, Ruscito P, Marzetti A, Marzetti F. Surgical management of parapharyngeal space tumours: results of 10year followup. Acta Otorhinolaryngol Ital. 2009; 29: 10-15

2. Monaca D, Bartoli D, Battisti A, Oriana. Parapharyngeal space benign tumours: Our experience. Journal of CranioMaxillofacial Surgery 2014; 42: 101-5

3. Horowitz G, Ben-Ari O, Wasserzug O, Weizman N, Yehuda M, Fliss DM. The Transcervical Approach for Parapharyngeal Space Pleomorphic Adenomas: Indications and Technique. February 27, 2014; 10.1371/journal.pone.0090210

4. Nayak UK, Choudhary S, Rao JJ. et al. Surgical Management of some unusual Parapharyngeal Space Tumors. Indian J Otolarynol Head Neck Surg 2001; 53: 281-4

5. Carrau RL, Mays EN, Johnson JT. Management of Tumors arising in Parapharyngeal Space; Laryngoscope 1990; 1000: 583-9

6. Stanley RE. Parapharyngeal Space Tumors; Ann Acad Med Singapore 1991; 20: 589-96

7. Som PM, Biller HG, Lawson N. Tumors of Parapharyngeal Space: Preoperative Evaluation, Diagnosis and Surgical Approaches. Ann Otol Rhino Laryngol 1981; 90: 3-15

8. Kletzer GR, Smith PG, Bigelow DC. et al. Management of High Parapharyngeal Space Tumors. Ear Nose 
Throat J 1981; 70: 639-47.

9. Dubner S, Spiro RH. Median Mandibulotomy: A Critical Assessment. Head Neck 1991; 13: 389-93

10. Work WP. Parapharyngeal and Salivary gland Neoplasms. Otlaryngol Clin North Am 1997; 10: 421-6.

11. Langer E, Negro AD, Akashi HK, Pareira P, Araujo C, Tincani AJ, Martins AS. Sau Paulo Medical Journal 2007; 125: ISSN: $1516-3180.1$

12. Rajasekar MK, Vijaynivas A. Parapharyngeal tumours our experience. Otolaryngology Online Journal 2015; Vol. 5: ISSN: 2250-0359
13. Pang KP, Goh CHK, Tan FM. Parpharyngeal Space Tumors: An 18 year review; J Laryngology and Otology 2002; 116: 107-17

14. Sperandio M, Di Poce I, Ricci A, Di Trapano R, Costanzo E, Di Cello P, Pelle F, Izzo L, Simonetti G. Malignant Peripheral Nerve Sheath Tumour: CT and MRI Findings. Case Reports in Radiology 2013; Article ID 517879

15. Shinghal T, Bissada E, Chan HB, Robert E, Wood RE, Eshetu G, Atenafu,D, Brown DH, Gilbert EW, Gullane PJ, Jonathan C, Irish JC, Waldron J, Goldstein DP. Medial Mandibulotomies: Is there sufficient space in the midline to allow a mandibulotomy without compromising the dentition? Journal of Otolaryngology - Head and Neck 2013; 42: 32 